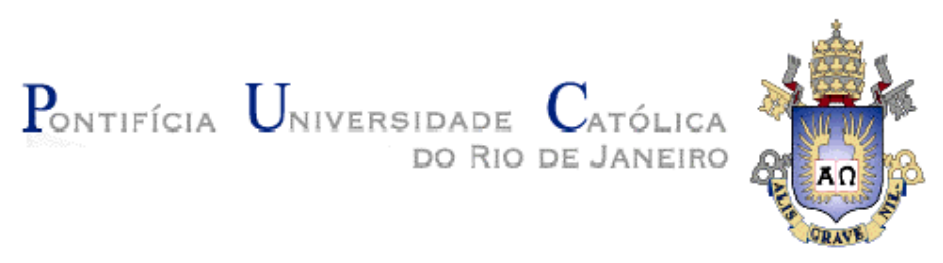

Daniel Simão Nascimento

O Problema da akrasia em Platão e Aristóteles

Tese de Doutorado

Tese apresentada ao Programa de PósGraduação em Filosofia do Departamento de Filosofia da PUC-Rio como parte dos requisitos parciais para obtenção do título de Doutor em Filosofia.

Orientador: Profạ. Maura Iglésias

Rio de Janeiro Abril de 2013 


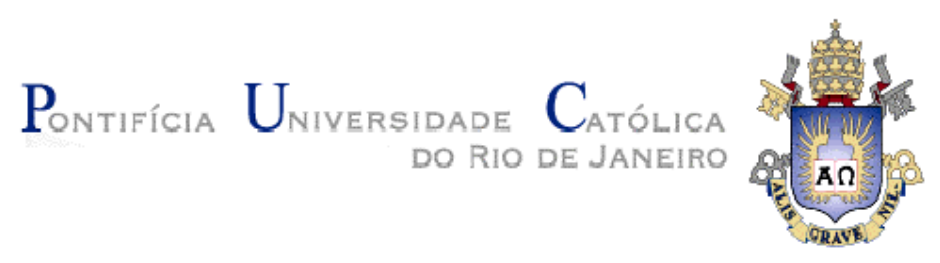

Daniel Simão Nascimento

\section{O Problema da akrasia em Platão e Aristóteles}

Tese apresentada como requisito parcial para obtenção do título de Doutor pelo Programa de Pós-Graduação em Filosofia do Departamento de Filosofia do Centro de Teologia e Ciências Humanas da PUC-Rio. Aprovada pela Comissão Examinadora abaixo assinada.

\section{Prof ${ }^{a}$. Maura Iglésias}

Orientadora

Departamento de Filosofia - PUC-Rio

Prof. Danilo Marcondes de Souza Filho Departamento de Filosofia - PUC-Rio

Prof ${ }^{a}$. Ana Flaksman Universidade Federal do Estado do Rio de Janeiro - UNIRIO

Profa. Priscilla Tesch Spinelli Universidade Federal do Rio Grande do Sul - UFRGS

Prof? . Maria Inês Senra Anachoreta Universidade do Estado do Rio de Janeiro - UERJ

Profa. Denise Portinari Coordenadora Setorial do Centro de Teologia e Ciências Humanas

Rio de Janeiro, 17 de abril de 2013. 
Todos os direitos reservados. É proibida a reprodução total ou parcial do trabalho sem autorização da universidade, da autora e do orientador.

\section{Daniel Simão Nascimento}

Daniel Simão Nascimento graduou-se emHistóriapelaUniversidade Federal Fluminense (2003). Como bolsista da CAPES, cursou o mestrado (2007) e o doutorado (2013) emFilosofiapelaPontifíciaUniversidadeCatólica do Rio de Janeiro. Durante o doutorado, e também com o apoio da CAPES, cursou um estágiodoutoralnaUniversidade Paris 1 Panthéon Sorbonne, sob a orientação da professoraAnnickJaulin.

Ficha Catalográfica

Nascimento, Daniel Simão

O problema da akrasia em Platão e Aristóteles / Daniel Simão Nascimento ; orientador: Maura Iglésias. - 2013.

$271 \mathrm{f} . ; 30 \mathrm{~cm}$

Tese (doutorado)-Pontifícia Universidade Católica do Rio de Janeiro, Departamento de Filosofia, 2013.

Inclui bibliografia

1. Filosofia - Teses. 2. Akrasia. 3. Platão. 4. Aristóteles. 5. Eurípides. 6. Voluntário. I. Iglésias, Maura. II. Pontifícia Universidade Católica do Rio de Janeiro. Departamento de Filosofia. III. Título.

CDD: 100 


\section{Agradecimentos}

À PUC-Rio pelos auxílios constantes concedidos ao longo do mestrado e do doutorado.

À CAPES pelas bolsas de estudos que permitiram não somente o doutorado, mas também um ano de estágio doutoral na França que foi fundamental para o resultado obtido.

Aos funcionários do departamento pela atenção e o apoio.

À professora Maura Iglésias pela orientação e por todos os diálogos, os que lemos e os que travamos, ao longo desses quatro anos.

À professora Annick Jaulin pela recepção na Universidade de Paris I, pelo tempo e cuidado dispensados na discussão desse trabalho.

À Priscilla Spinelli, Anna Flaksman e Maria Inês Anachoreta pelas ricas contribuições ao desenvolvimento do trabalho.

Aos familiares pelo suporte e carinho.

Ao meu pai Álvaro pela tão dedicada revisão.

À Gisele, por construirmos veredas. 


\section{Resumo}

Nascimento, Daniel Simão; Iglésias, Maura. O problema da akrasia em Platão e Aristóteles. Rio de Janeiro, 2013. 271p. Tese de Doutorado Departamento de Filosofia, Pontifícia Universidade Católica do Rio de Janeiro.

Se ainda hoje permanece a dúvida a respeito da possibilidade de se encontrar, na filosofia grega, um conceito que possa corresponder ao conceito latino de vontade, ninguém parece questionar o fato de que foram os gregos os primeiros filósofos a tentar compreender o fenômeno que hoje chamamos de 'fraqueza da vontade' - e que eles chamavam simplesmente akrasia.

Embora o primeiro filósofo que tenha empregado tal termo ao discutir o problema tenha sido Aristóteles (EN VII.1), a primeira discussão filosófica acerca da akrasia pode ser encontrada no Protágoras de Platão. Lá, o fenômeno que é discutido recebe o nome de 'ser vencido pelos prazeres'. Como sabemos, Sócrates nega que tal fenômeno seja possível e afirma o famoso paradoxo Socrático segundo o qual ninguém erra voluntariamente.

Nosso trabalho tem por objetivo principal traçar uma comparação entre o problema da akrasia nas filosofias de Platão e de Aristóteles, para que possamos compreender melhor algo que até hoje é motivo de grandes controversas, a saber, em que media Aristóteles se afasta da explicação socrática da akrasía e em que sentido ele a aceita. Para tal, procuramos esclarecer não somente as diferenças notáveis entre os dois autores no que diz respeito à descrição da akrasia mas também à maneira como cada um dos autores concebem o ato voluntário. Além disso, dedicamos nossa introdução à discussão de duas peças de Eurípides, Hipólito e Medéia, com o objetivo de iluminar isso que poderíamos chamar, talvez, de raízes pré-filosóficas do problema.

\section{Palavras-chave:}

Akrasia; Platão; Aristóteles; Eurípides; Voluntário. 


\section{Abstract}

Nascimento, Daniel Simão; Iglésias, Maura. (Advisor). The Problem of Akrasia in Plato and Aristotle. Rio de Janeiro, 2013. 271p. Thesis Departamento de Filosofia, Pontifícia Universidade Católica do Rio de Janeiro.

Although to this day some doubt remains about whether we can find, in Greek philosophy, a concept that corresponds to the latin notion of the will, nobody seems to question the fact that the greek philosophers were the first to try to understand the phenomenon which today we call 'weakness of the will' - and that they called akrasia.

Although the first philosopher employed this term when discussing the problem was Aristotle (EN VII.1), the first philosophical discussion about akrasia is to be found in Plato's Protagoras. In this dialogue, the phenomenon that is discussed is called 'being defeated by pleasures'. As we know, Socrates denies that such a thing is even possible and affirms his famous paradox according to which nobody errs willingly.

This work's main goal is to compare the problem of akrasia in Plato and Aristotle, so that we can better understand something which is still a matter of great dissent: how much of the Socratic explanation of the phenomenon is accepted by Aristotle and how much of it is discarded? In order to answer this question, I've tried to highlight the differences that separate the authors in what concerns both their description of akrasia and the way they conceive the voluntary act. I've also dedicated the introduction of the work to a discussion about two plays of Euripides, Hyppolitus and Medea, with the objective of shedding some light in what we might perhaps call the 'pre-philosophical roots' of the problem.

\section{Key-Words:}

Akrasia; Plato; Aristotle; Euripides; Voluntary. 


\section{Sumário}

1. Introdução …................................................................ 11

1.1. Kratos em Homero .................................................... 11

1.2. Eurípides e o conflito entre razão e paixão ........................... 13

1.3. A akrasia em Eurípides segundo Terence Irwin .................. 20

1.4. Medéia .............................................................................. 23

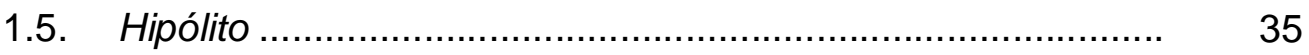

1.6. Um outro olhar sobre a akrasia em Eurípides .................... 43

2. O Protágoras ...................................................................... 48

2.1. Akrasia e intelectualismo socrático .................................. 48

2.2. O relato da multidão e a pergunta de Sócrates .................... 49

2.3. O prazer e o bem ............................................................ 52

2.4. O hedonismo do Protágoras .............................................. 54

2.5. A metretike e a força das aparências ................................ 59

2.6. Opinião e phantasia ...................................................... 63

2.7. A conclusão do argumento socrático ................................. 69

2.8. Platão, Mill e o utilitarismo ............................................ 75

2.9. O argumento socrático no contexto do Protágoras .............. 79

2.10. Justiça, virtude e metretike ........................................... 81

3. O Górgias .................................................................... 83

3.1. Plano do capítulo .......................................................... 83 
3.2. A definição da retórica .......................................................

3.3. O orador, o tirano e a felicidade: $\mathrm{o}$ argumento do poder ....... 89

3.4. Justiça e utilidade ............................................................. $\quad 97$

3.5. O ato voluntário segundo Sócrates …………..................... 101

3.6. Injustiça e vergonha ........................................................ 103

3.7. Sobre as aparentes contradições entre o Górgias e o Protágoras .......................................................................... 105

3.8. Cálicles, a retórica e o binômio natureza e convenção ......... 105

3.9. Hedonismo, akolasia e mais algumas aparentes

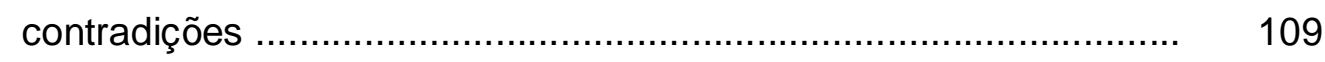

3.10. Hedonismo e desenvolvimento no Górgias de Platão .......... 114

3.11. Sobre o maior dos males ................................................ 115

3.12. O ato voluntário e o problema da akrasia ............................ 117

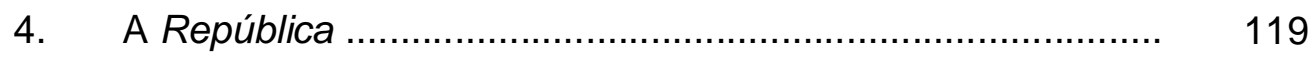

4.1. Os fundamentos da interpretação tradicional ....................... 119

4.2. A tripartição da alma e o conflito psíquico no livro IV da

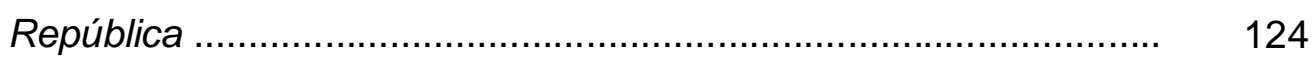

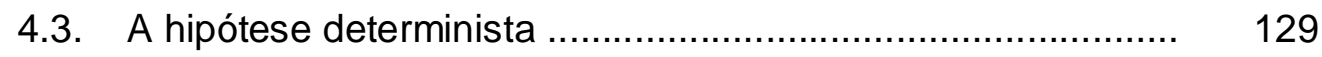

4.4. As almas injustas dos livros VIII e IX ................................. 135

4.5. A enkrateia na República ................................................ 148

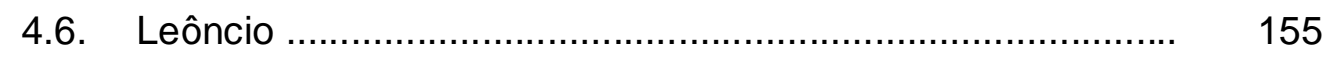

4.7. Platão e o 'princípio valor-força' ........................................... 159

5. O ato voluntário em Aristóteles …………………................... 164

5.1. As duas investigações do conceito ………………............. 164

5.2. Aristóteles e o paradoxo socrático …………......................... 164

5.3. Reprovação, louvor e os limites do constrangimento ............ 168

5.4. Os atos feitos por ignorância ............................................ 176

5.5. Involuntário e não voluntário ............................................ 180

5.6. Sobre o papel do conhecimento na ação voluntária .............. 185

5.7. O vício, assim como a virtude, é voluntário ………………... 194

5.8. O ato voluntário e o problema da akrasia (II) ....................... 197 


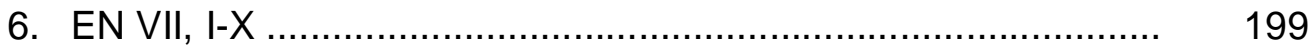

6.1. O método da investigação ................................................. 199

6.2. A primeira opinião: akrasia e malakia, enkrateia e karteria ... 200

6.3. A segunda opinião: autocontrole e obstinação ..................... 204

6.4. A terceira opinião e a explicação platônica da akrasia ......... 207

6.5. Temperança, autocontrole e algumas formas de akrasia por analogia: as três últimas opiniões .................................................. 214

6.6. Sobre os objetos da akrasia ........................................... 215

6.7. A akrasia theriodes e a akrasia tou thymou ........................ 220

6.8. Os dois sentidos de 'conhecer' ........................................... 224

6.9. Sobre o silogismo prático …………………………......... 226

6.10. O silogismo prático na ação incontinente ........................... 231

6.11. Sobre o suposto intelectualismo do livro VII da Ética a Nicômaco ........................................................................ 239

6.12. Os dois tipos de akrasia: impulsividade e fraqueza ............. $\quad 249$

6.13. Aristóteles e o 'princípio valor-força' ...................................... 251

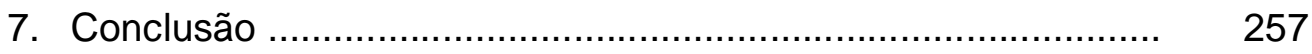

8. Referências Bibliográficas ........................................................ 266 
"One must start out with error and convert it into truth. That is, one must reveal the source of error, otherwise hearing the truth won't do any good. The truth cannot force it's way in when something else is occupying it's place. To convince someone of the truth, it is not enough to state it, but rather one must find the path from error to truth."

- Ludwig Wittgenstein, Remarks on Frazer's Golden Bough.

"Les études doivent avoir pour but de donner à l'esprit une direction qui lui permette de porter des jugements solides et vrais sur tout ce qui se presente à lui." - Descartes, Règles pour la direction de l'Esprit. 